\title{
Surgical Management of Massive Postpartum Hemorrhage with Uterine Atony
}

\author{
Apichart Chittacharoen* \\ Department of Obstetrics \& Gynaecology, Mahidol University, Thailand
}

Submission: May 16, 2017 ; Published: May 30, 2017

*Corresponding author: Apichart Chittacharoen, Department of Obstetrics \& Gynaecology, Faculty of Medicine, Ramathibodi Hospital, Mahidol University, Thailand, Email: apichart.chi@mahidol.ac.th

\section{Opinion}

Postpartum hemorrhage (PPH) is an obstetrical emergency that can follow vaginal or cesarean delivery. It is a major cause of maternal morbidity, with sequelae such as shock, renal failure, acute respiratory distress syndrome, co agulopathy, and Sheehan's syndrome [1]. PPH is also one of the top five causes of maternal mortality in both high income and low income countries, although the absolute risk of death is much lower in the former than the latter ( 1 in 100,000 versus 1 in 1000 births) [2]. Life-threatening PPH occurs with a frequency of 1 in 1000 deliveries in the developed world. The incidence of PPH varies widely, depending upon the criteria used to define the disorder. A reasonable estimate is 1 to 5 percent of deliveries [3]. $\mathrm{PPH}$ is best defined and diagnosed clinically as excessive bleeding that makes the patient symptomatic (eg, lightheadedness, vertigo, syncope) and/or results in signs of hypovolemia (eg, hypotension, tachycardia, or oliguria). Other definitions that have been proposed can be problematic. The most common definition of PPH is estimated blood loss $\geq 500 \mathrm{~mL}$ after vaginal birth or $\geq 1000 \mathrm{~mL}$ after cesarean delivery [4]. Estimates of blood loss at delivery are subjective and generally inaccurate. Studies have suggested that caregivers consistently underestimate actual blood loss. Another proposal suggests using a $10 \%$ fall in hematocrit value to define $\mathrm{PPH}$, but this change is dependent on the timing of the test and the amount of fluid resuscitation given [5]. More importantly, the diagnosis would be retrospective, perhaps useful for research but not so in the clinical setting.

If the initial interventions described above are not immediately successful in controlling hemorrhage, the woman is placed in stirrups in a room with facilities for general anesthesia and both vaginal and abdominal surgery. The primary source of bleeding, uterine or lower genital tract, can usually be readily determined by visualizing the birth canal and by palpating the uterus. Adequate assistance, exposure, lighting, instruments, and anesthesia are necessary to perform a thorough examination.
Although uterine packing was advocated for treating PPH in the past, it fell out of use largely due to concerns of concealed hemorrhage and uterine over distension. In recent years, however, several modifications of this procedure have allayed these concerns. Balloon tamponade using eg. a Foley catheter, a Sengstaken-Blakemore tube, Bakri tamponade balloon, Rusch hydrostatic balloon has been shown to effectively control postpartum bleeding and may be useful in several settings: uterine atony, retained placental tissue, and placenta accrete [6-12]. The balloon have open tips, which permit continuous drainage from the uterus. Furthermore, if the concern for concealed hemorrhage still exists, ultrasound can more effectively detect a developing hematoma when the contrast is a fluid-filled balloon as opposed to blood-saturated gauze. Thus, this technique has the advantage of being not only therapeutic but also diagnostic when used in combination with ultrasonography in differentiating the various etiologies described above. Additionally, if intrauterine blood loss exceeds $5 \mathrm{~cm} / \mathrm{sec}$, the actual site of arterial bleeding can be pinpointed sonographically using power angiography mode against the contrast of the fluid-filled balloon.

Ideally, hemostatic defects will have been corrected prior to invasive interventions, but this can be difficult in the presence of continuous brisk hemorrhage. In such cases, blood product replacement concurrent with initiation of invasive procedures is necessary. Bilateral ligation of the uterine vessels (O'Leary stitch) to control PPH has become the first-line procedure for controlling uterine bleeding in the parturient at laparotomy [13]. It is a more attractive option than internal iliac artery ligation because the uterine arteries are easily accessible, the procedure is more successful, and the field of dissection generally is not near the ureters and the iliac veins. After identification of the ureter, a\# 0 or \#1 chromic catgut or polyglycolic acid suture on a large curved needle is passed through the lateral aspect of the lower uterine segment as close to the cervix as possible, then back 
through the broad ligament just lateral to the uterine vessels. It is then tied to compress these vessels. If this does not succeed in controlling bleeding, the vessels of the utero-ovarian arcade are similarly ligated just distal to the cornua by passing a suture ligature through the myometrium just medial to the vessels.

Uterine compression sutures are an effective method for reducing postpartum hemorrhage and avoiding hysterectomy. Limited follow-up of women who have had a uterine compression suture suggests that there are no adverse effects on future pregnancy. The B-Lynch suture envelops and compresses the uterus, similar to the result achieved with manual uterine compression. It has been highly successful in controlling uterine bleeding from atony when other methods have failed. The technique is relatively simple to learn, appears safe, and preserves future reproductive potential [14]. A large needle with \#1 or \#2 polyglycolic acid suture is used to enter and exit the uterus in the lateral lower anterior segment. The stitch is looped over the fundus and another stitch is taken across the posterior lower uterine segment. The stitch is then looped back over the fundus and anchored by entering the lateral lower anterior uterine segment opposite and parallel to the initial bite. The free ends are tied down securely to compress the uterus. The myometrium should be manually compressed prior to tying down the sutures to facilitate maximal compression.

The success of B-Lynch suture technique has been replicated in other small series. The success rate of this procedure is 80 85\% [14-17]. The study between October 2004 and December 2011, at Department of Obstetrics \& Gynaecology, Faculty of Medicine, Ramathi bodi Hospital, Mahidol University showed that the B-Lynch suture was performed on 60 patients, to control intractable $\mathrm{PPH}$ that did not respond to uterotonic agents. In those cases where the etiology of PPH was uterine atony, the B-Lynch suture was successful in $84 \%$ of the cases. Hysterectomy was avoided in 50 cases.

Other techniques which have been reported in small case series represent modifications of the B-Lynch suture. Hayman described placement of two to four vertical compression sutures from the anterior uterine wall to the posterior uterine wall without hysterotomy. A transverse cervicoisthmic suture can also be placed if needed to control bleeding from the lower uterine segment [18]. Pereira described a technique in which a series of transverse and longitudinal sutures of a delayed absorbable multifilament suture are placed around the uterus via a series of bites into the subserosal myometrium, without entering the uterine cavity [19].

\section{Conclusion}

PPH is a common complication of childbirth and a leading cause of maternal morbidity and mortality. Clinicians should identify risk factors before and during labor so that care may be optimized for high-risk women. The uterine compression suture
(B-Lynch suture) is more available method of conservative surgical management of massive PPH.

\section{References}

1. Chichakli LO, Atrash HK, MacKay AP, Musani AS, Berg CJ (1999) Pregnancy-related mortality in the United States due to hemorrhage: 1979-1992. Obstet Gynecol 94(5 Pt 1): 721-725.

2. Centers for Disease Control and Prevention (CDC) (1999) Healthier mothers and babies. MMWR Morb Mortal Wkly Rep 48(38): 849-858.

3. Koonin LM, MacKay AP, Berg CJ, Atrash HK, Smith JC (1997) Pregnancyrelated mortality surveillance? United States, 1987-1990. MMWR CDC Surveill Summ 46(4): 17-36.

4. Postpartum Hemorrhage (1998) ACOG Technical Bulletin No. 243. American College of Obstetricians and Gynecologists, Washington, USA.

5. Cunningham FG, Gant NF, Leveno KJ (2001) Conduct of normal labor and delivery. In: Williams (Ed.), Obstetrics. (21 $1^{\text {st }}$ edn), McGraw-Hill, New York, USA, pp. 320-325.

6. Marcovici I, Scoccia B (1999) Postpartum hemorrhage and intrauterine balloon tamponade: a report of three cases. J Reprod Med 44(2): 122126.

7. De Loor JA, van Dam PA (1996) Foley catheters for uncontrollable obstetric or gynecologic hemorrhage. Obstet Gynecol 88(4 Pt 2): 737.

8. Chan C, Razvi K, Tham KF, Arulkumaran S (1997) The use of a Sengstaken-Blakemore tube to control postpartum hemorrhage. Int J Gynaecol Obstet 58(2): 251-252.

9. Katesmark M, Brown R, Raju KS (1994) Successful use of a SengstakenBlakemore tube to control massive postpartum haemorrhage. $\mathrm{Br} \mathrm{J}$ Obstet Gynaecol 101(3): 259-260.

10. Bakri YN, Amri A, Abdul Jabbar F (2001) Tamponade-balloon for obstetrical bleeding. Int J Gynaecol Obstet 74(2): 139-142.

11. Danso D, Reginal PW (2006) Internal uterine tamponade. In: B-Lynch C, Keth LG, Lalonde AB, Karoshi M, (Eds.), A textbook of postpartum hemorrhage: A comprehensive guide to evaluation, management and surgical intervention. Sapiens Publishing, Duncow, UK, pp. 263-267.

12. Johanson R, Kumar M, Obrai M, Young P (2001) Management of massive postpartum haemorrhage: use of a hydrostatic balloon catheter to avoid laparotomy. Br J Obstet Gynaecol 108: 420-422.

13. 0"Leary JA (1995) Uterine artery ligation in the control of postcesarean hemorrhage. J Reprod Med 40(3): 189-193.

14. B-Lynch C, Coker A, Lawal AH, Abu J, Cowen MJ (1997) The B-Lynch surgical technique for the control of massive postpartum haemorrhage: an alternative to hysterectomy? Five cases reported. Br J Obstet Gynaecol 104(3): 372-375.

15. Dacus JV, Busowski MT, Busowski JD (2000) Surgical treatment of uterine atomy employing the B-Lynch technique. J Matern Fetal Med 9: 194-196.

16. Ferguson JE, Bourgeois FS, Underwood PB (2000) B-Lynch suture for postpartum hemorrhage. Obstet Gynecol 95(6): 1020-1022.

17. Price N, B-Lynch C (2005) Technical description of the B-Lynch brace suture for treatment of massive postpartum hemorrhage and review of published cases. Int J Fertil Womens Med 50(4): 148-163.

18. Hayman RG, Arulkumaran S, Steer PJ (2002) Uterine compression sutures: surgical management of postpartum hemorrhage. Obstet Gynecol 99(3): 502-506.

19. Pereira A, Nunes F, Pedroso S, Saraiva J, Retto H, et al. (2005) Compressive uterine suture to treat postpartum bleeding secondary to uterine atony. Obstet Gynecol 106(3): 569-572. 
This work is licensed under Creative Commons Attribution 4.0 Licens

DOI:_10.19080/JGWH.2017.05.555653
Your next submission with Juniper Publishers will reach you the below assets

- Quality Editorial service

- Swift Peer Review

- Reprints availability

- E-prints Service

- Manuscript Podcast for convenient understanding

- Global attainment for your research

- Manuscript accessibility in different formats

( Pdf, E-pub, Full Text, Audio)

- Unceasing customer service

Track the below URL for one-step submission https://juniperpublishers.com/online-submission.php 